\title{
Application of Nipple-Areolar Complex Impending Necrosis with Light-Emitting Diode Treatment for Immediate Breast Reconstruction after Nipple-Sparing Mastectomy
}

\author{
Seok Min Yoon ${ }^{1}$ \\ Yu Gil Park ${ }^{2}$ \\ Eun Soo Park ${ }^{2}$ \\ Chang Yong Choi $^{1}$
}

\begin{abstract}
${ }^{1}$ Department of Plastic and Reconstructive Surgery, College of Medicine, Soonchunhyang University, Gumi, Korea

${ }^{2}$ Department of Plastic and Reconstructive Surgery, Soonchunhyang University College of Medicine, Bucheon, Korea
\end{abstract}

\begin{abstract}
Background and Objectives
Necrosis of the nipple-areolar complex (NAC) is a devastating complication of reconstructive breast surgery. Noncontact, Lightemitting diode (LED) phototherapy is an attractive therapy that promotes wound healing by stimulating the fibroblasts and increasing cell activities of the wound bed. We investigated the clinical efficacy of LED phototherapy to minimize nipple-areolar complex necrosis after nipplesparing mastectomy with immediate breast reconstruction.
\end{abstract}

\section{Materials and Methods}

Then patients received LED phototherapy. OMEGA Light ${ }^{\circledR}$ (Esmedi global, Seoul, Koreal has 4 different wavelengths that ranged from $423 \mathrm{~nm}$ to 640 $\mathrm{nm}$. A $640 \mathrm{~nm}$ LED red light source was used. Patients received LED phototherapy for 20 minutes, twice a day, until postoperative week one. To reduce bacterial contamination and promote quick granulation and reepithelization, wound dressings were changed twice a day after phototherapy.

\section{Results}

Patients at risk of NAC ischemia showed clinical signs, including discoloration, edema of the nipple, and altered capillary refilling within the first 24 hours. Although NAC appeared to be ischemic and started to demarcate in the early postoperative period, there were no significant tissue loss. All ischemic NACs healed by secondary intention. Despite the presence of some demarcated areas in the early postoperative period, natural-looking NACs were restored in all breasts.

\section{Conclusion}

Accepted June 19, 2017

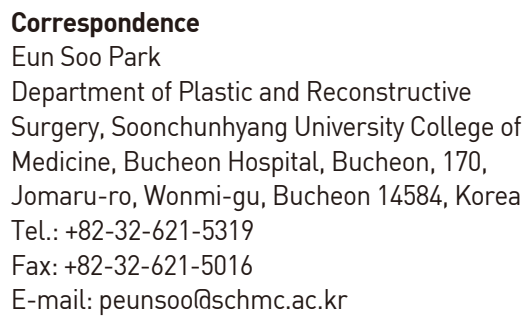

*No potential conflict of interest relevant to this article was reported.

(C) Korean Society for Laser Medicine and Surgery

(c) This is an open access article distributed under the terms of the Creative Commons Attribution NonCommercial License (http://creativecommons.org/ licenses/by-nc/4.0) which permits unrestricted noncommercial use, distribution, and reproduction in any medium, provided the original work is properly cited.
The use of LED inducing a photobiomodulative reaction to ischemic NACs after breast reconstruction can be effective in reducing postoperative NAC full thickness necrosis and improving wound healing.

\section{Key words}

LED; NAC; Nipple sparing mastectomy; Reconstruction of breast 


\section{INTRODUCTION}

Breast cancer is second only to skin cancer as the most common cancer in women. Each year, approximately 215,000 women in the United States are diagnosed with breast cancer and tens of thousands of women undergo mastectomy for primary treatment. ${ }^{1}$ The resulting psychological disturbances in affected patients after mastectomy have been well-established. Breast reconstruction has been shown to help restore positive self-image and psychological well-being. Recently, autologous or implant-based breast reconstruction after mastectomy has been increasingly preferred worldwide as a breast cancer treatment option. ${ }^{2-6}$ In 2011, according to the American Society of Plastic Surgeons, nearly 100,000 women underwent postmastectomy breast reconstruction.?

Recently, skin-sparing mastectomy has been performed frequently in breast cancer surgery. Also, in cases where breast cancer size is relatively small and distant from the nipple, there is a case of mastectomy for preserving the nipple. However, in these cases, skin necrosis may occur according to the thickness of the skin flap and the degree of preservation of the skin vascular lesion. Particularly, skin necrosis can occur frequently, if the nipple-areolar complex (NAC) is preserved. Resecting the tissue located below the NAC causes injury to local perforators and leads to a risk of ischemia in the NAC. ${ }^{8,9}$ There is a risk of delayed healing of the wound, transforming of the NAC complex and infrequently, infection of secondary pathogens.

In the immediate breast reconstruction, partial necrosis of the NAC is distressing. In order to prevent this, careful attention is paid to the preservation of the skin blood circulation, and it is important to protect the protruding nipples by non compressive dressing. In order to prevent such complication, we applied OMEGA light-emitting diode (LED) to patients who underwent necrotic change of NAC after nipple sparing mastectomy (NSM).

\section{MATERIALS AND METHODS}

A retrospective cohort study was performed on 10 patients who underwent post NSM breast reconstruction from January of 2015 to December of 2016. All patients included in the study had impending necrosis in the NAC. Patients with contraindication of nipple sparing were excluded, and additional procedures such as augmentation and reduction were also excluded.

Mastectomy was performed by three breast surgeons with periareolar incision and reconstruction was per- formed by single plastic surgeon. Reconstruction was performed mainly with latissimus dorsi musculocutaneous flap and implant insertion. 10 patients underwent LED after surgery. Unlike the existing LED equipment, it does not have a pedestal and it is convenient to lie on the bed (Fig. 1). OMEGA Light ${ }^{\circledR}$ (Esmedi global, Seoul, Koreal has 4 different wavelengths ranging from $423 \mathrm{~nm}$ to $640 \mathrm{~nm}$. A $640-\mathrm{nm}$ LED red light source was used. The purpose of the LED is to improve vascular circulation to the NAC and promote wound healing. Patients received a LED phototherapy for 20 minutes twice a day until a week postoperatively. To reduce bacterial contamination and promote quick granulation and reepithelization, wound dressings were changed twice a day after phototherapy.

We reviewed preoperative and postoperative photographs, office charts, and hospital records retrospectively. Physical examination and photograph review were performed on the day after surgery $\left(T_{0}\right)$, one week $\left(T_{1}\right)$, and three weeks $\left(T_{2}\right)$ after surgery. We evaluated the capillary refill, color, temperature and skin turgor of the wound at three period evaluations after the surgery. And we applied the grading system based on postoperative photo. Grade 0 for normal skin and grade 1 for partial thickness ischemic appearance requiring local wound care. And grade 2 was defined as progression of necrosis with full thickness and was assessed only if a surgical procedure was required (Fig. 2). Grade evaluation included ischemia of nipple, areolar and incision site.

\section{RESULTS}

Seven patients (70\%) were treated with latissimus

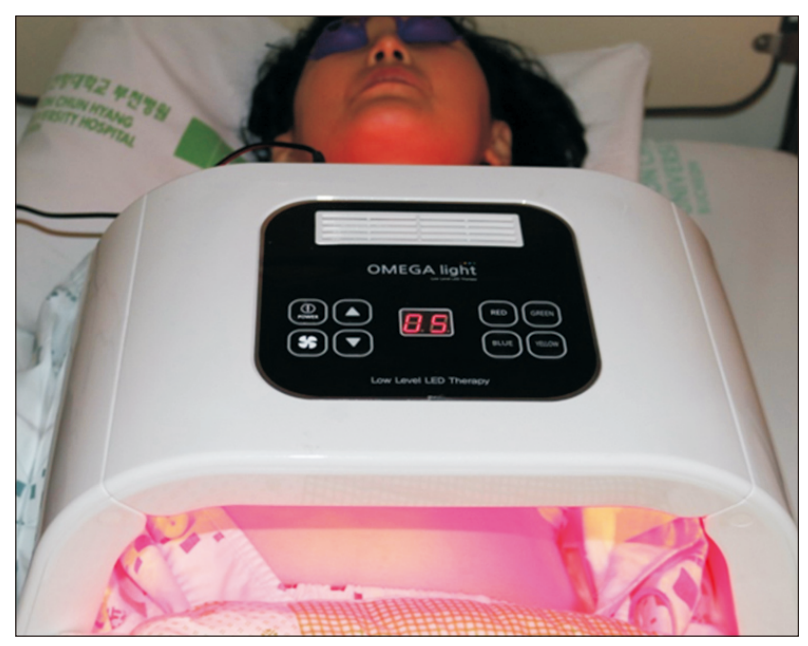

Fig. 1. Unlike the existing light-emitting diode (LED) equipment, there is no pedestal, it is easy to lay on the bed and convenient to apply. 

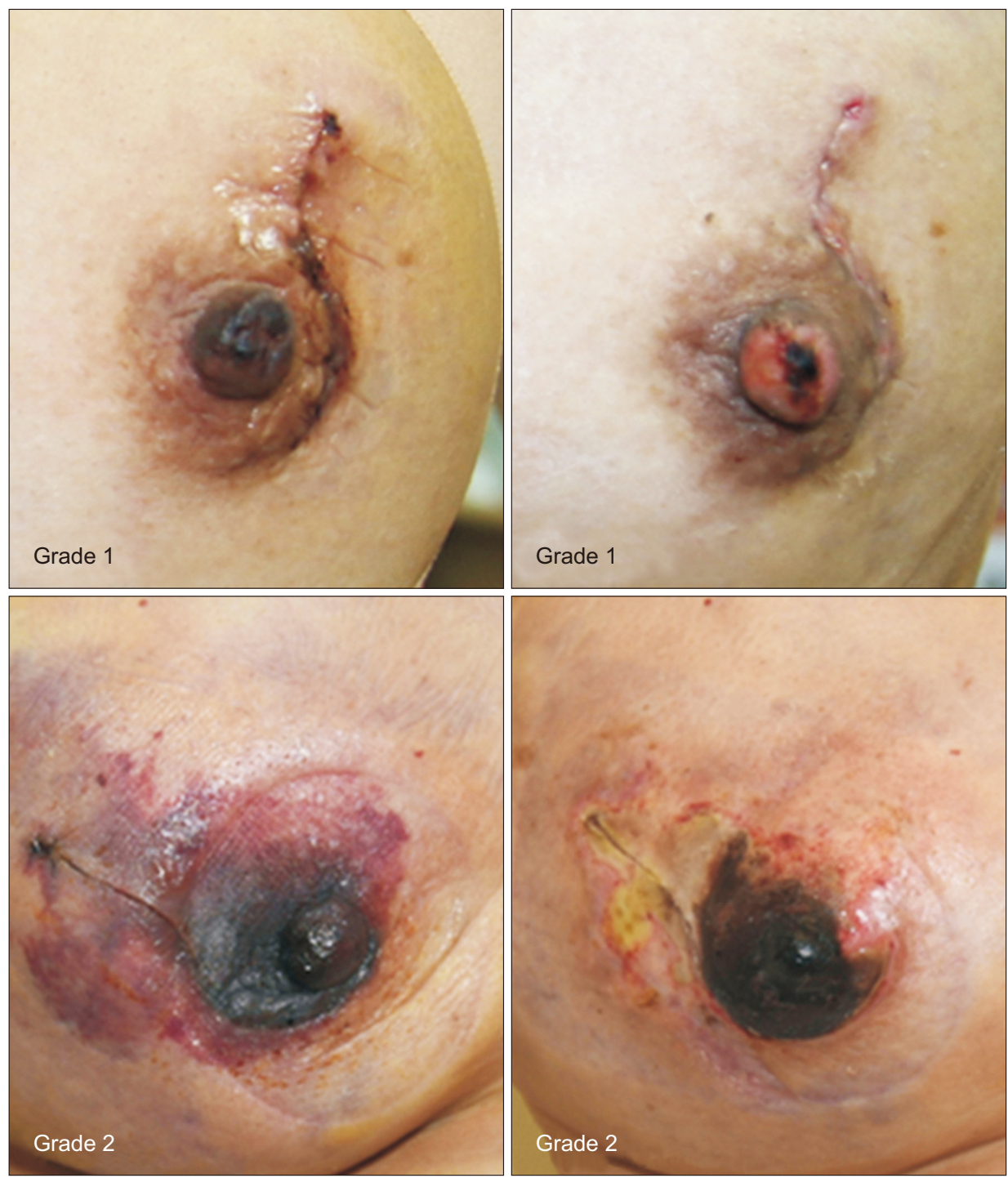

Fig. 2. Photograph review grade. Partial thickness ischemic appearance requiring local wound care was grade 1 , and full thickness ischemic appearance requiring surgical procedure was grade 2 . dorsi musculocutaneous flap and implant insertion, and 3 patients (30\%) were treated with only latissimus dorsi musculocutaneous flap. All patients underwent LED phototherapy. Partial thickness necrotic changes were observed in NAC and incision sites before LED treatment.

When follow up was performed 1 week after surgery, 4 cases who were evaluated as grade 1 were normalized. And after 3 weeks follow up, wound healing was completed with grade 0 in all cases. Table 1 summarizes about results.

There were no other major complications such as wound infection and NAC malposition. Patients receiving LED phototherapy experienced a minimization in the incidence of full thickness necrosis of the nipple. And we received favorable responses about additional effects such as pain relief.
Table 1. Comparision of the grade about evaluation periods

\begin{tabular}{cccc}
\hline & Grade 0 & Grade 1 & Grade 2 \\
\hline $\mathrm{T}_{0}$ & 0 & 10 & 0 \\
$\mathrm{~T}_{1}$ & 4 & 6 & 0 \\
$\mathrm{~T}_{2}$ & 10 & 0 & 0 \\
\hline
\end{tabular}

\section{CASE}

A 48-year-old female patient underwent NSM by the breast surgeon for left breast cancer and performed latissimus dorsi musculocutaneous flap and implant insertion by plastic surgeon. Patient received a LED phototherapy for 20 minutes twice a day until a week postoperatively. Physical examination and photograph review were performed on the day after surgery, one week, and three 

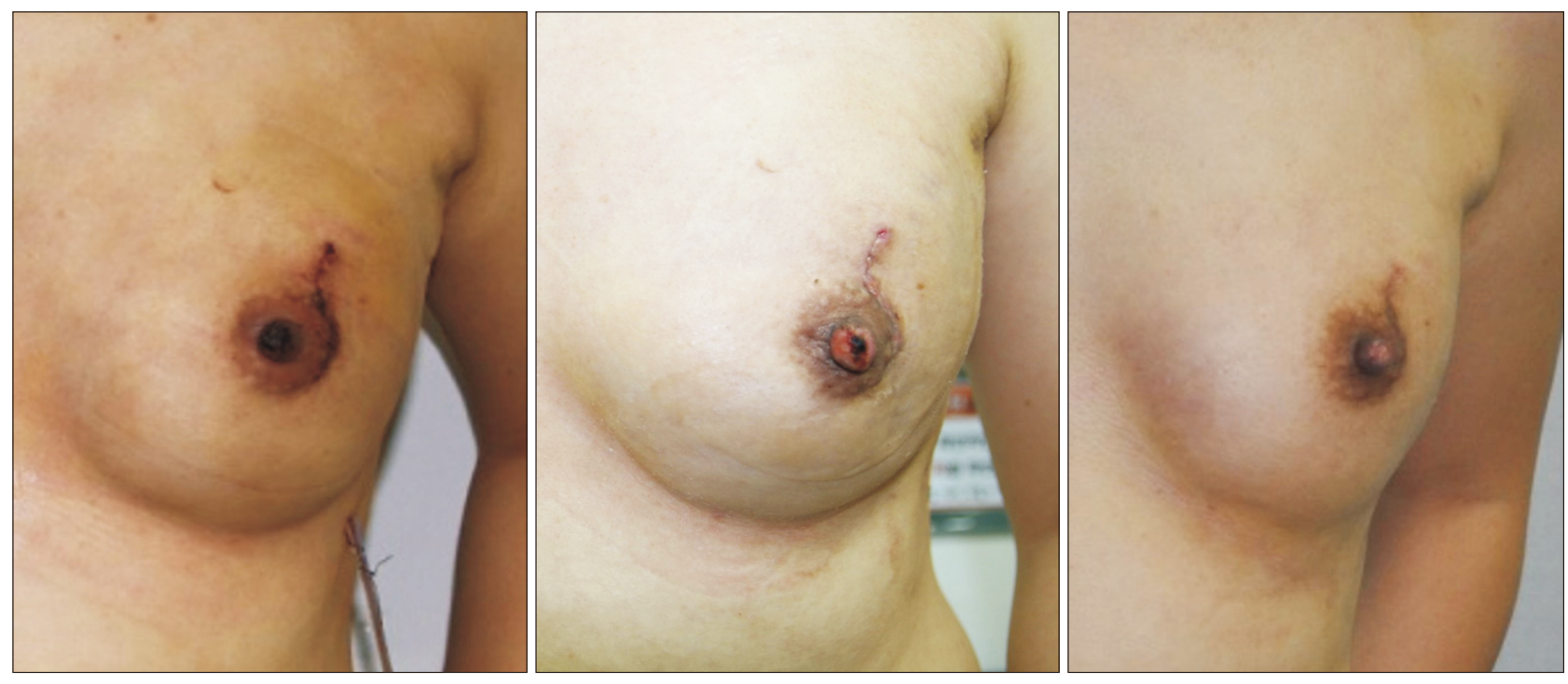

Fig. 3. Postoperative day 1, week 1, and week 3 postoperative photographs of 48-year-old woman with left breast cancer who underwent nipplesparing mastectomy and latissimus dorsi musculocutaneous flap with implant based breast reconstruction. By LED treatment, the necrotic tissue observed at the nipple-areolar complex and incision site gradually normalized, and color and viability were recovered.

weeks after surgery. NAC and incision site, which were evaluated as grade 1 before LED treatment, were normalized to grade 0 after LED treatment. Wound color and viability were recovered (Fig. 3). The remaining scar was treated with laser treatment.

\section{DISCUSSION}

Several oncological studies have established that NSM is associated with a reduced risk of local recurrence. ${ }^{10,11}$ Many studies have recommended that NSM only be performed in patients with peripheral tumors located no closer than $5 \mathrm{~cm}$ to the NAC. ${ }^{2}$ Several studies have described NAC necrosis after NSM. The reported incidence of NAC necrosis has been reported to range from $0 \%$ to $48 \%, 3,4,12,13$

As a result of this study, it is thought that the application of LED for minimization of NAC necrosis provides successful management. It has been found that LEDs promote wound healing, and red light having a wavelength of $640 \mathrm{~nm}$ has a high permeability up to $6 \mathrm{~mm}$ from the skin surface, thus promoting migration and proliferation of the fibroblast. It also affects the reepithelization of the wound and increasing of the blood flow. So we were able to prevent full thickness necrosis.

Low-level laser therapy (LLLT) is a laser with an output power of less than $1 \mathrm{~W}$ (watt). This laser, when calculated from the concept of energy including the laser irradiation time, shows a proper irritating effect without destroying the cells within the range of about 0.05 to $10 \mathrm{~J}$. The low power laser does not generate heat and transmits only the light energy to the inside of the body through the surface of the skin without any other damage. In addition, the body cells that absorb the laser beam convert the light energy into chemical energy that can heal the damage of the cell and use it for the healing and pain relief of the damaged area. This phenomenon is called the phtobiostimulation effect. The mechanism of promoting wound healing is known to be mitochondrial activation, ATP synthesis, promotion of DNA \& RNA synthesis, promotion of protein synthesis, regulation of enzyme reaction, $\mathrm{pH}$ control inside and outside cells, and activation of cell metabolism.

In addition, it is known that the degree of increase of DNA synthesis rate in vivo by laser wavelength is different, and cell activation is promoted in blue wavelength of 404 $\mathrm{nm}$ and $454 \mathrm{~nm}$, red wavelength of $620 \mathrm{~nm}$, and infrared wavelength of $760 \mathrm{~nm}$ and $830 \mathrm{~nm}$. And even if you use a different type of light than a laser, the same results can be obtained if the light has the same wavelength as that of the low-power laser. The result of this result is that it is possible to use various light sources. This suggests that the clinical effect of low power laser therapy is not due to the characteristics of the laser itself, but rather the wavelength of the laser itself. Therefore, it can be useful to increase the cell activity if the light source of the laser does not have the disadvantage, which usually the lasers have, and the wavelength is well absorbed by the cell. A 
representative example is a light emitting diode (LED). LED is a semiconductor element that emits light when a voltage is applied in the forward direction. In recent years, medical devices using LED as light sources instead of conventional low power laser devices have been increasingly used for medical purposes. Compared to conventional low-power lasers, LED phototherapy can be applied more easily to a large surface area treatment, shortening the procedure time, and emitting light with a wider range of wavelengths. LED has panels of various wavelengths (blue light, yellow light, green light, red light, infrared light, red light + infrared light) that can be mounted on the main body. Among them, red $(635 \mathrm{~nm})$ and infrared light sources $(830 \mathrm{~nm})$ are used for fibroblast proliferation, substrate synthesis, and stimulation of angiogenesis to improve wound healing. Omega light can also be used in four different wavelengths (red, blue, green, yellow) to solve various skin problems, as well as relieve pain and promote wound healing.

This study was limited to selective inclusion criteria and retrospective review. Mastectomy was performed by three general surgeons and the NAC necrosis was evaluated by subjective analysis so bias intervention is possible. In addition, according to the incision method, the viability of NAC may be affected, and we did not consider factors related to vascular circulation such as smoking history. In addition, the number of patients is small, so further study will be needed.

\section{CONCLUSION}

With a meticulous design, planning, and execution, $100 \%$ prevention of NAC ischemia and necrosis is not possible. Although the operative technique is considered more important, the use of LED inducing a photobiomodulative reaction to ischemic NACs after breast reconstruction can be effective to minimize postoperative NAC full thickness necrosis and improve wound healing. Moreoever, patients received additional benefits such as pain relief.

\section{REFERENCES}

1. Potter S, Brigic A, Whiting PF, Cawthorn SJ, Avery KN, Donovan $\mathrm{JL}$, et al. Reporting clinical outcomes of breast reconstruction: a systematic review. J Natl Cancer Inst 2011;103:31-46.
2. Spear SL, Hannan CM, Willey SC, Cocilovo C. Nipple-sparing mastectomy. Plast Reconstr Surg 2009;123:1665-73.

3. Komorowski AL, Zanini V, Regolo L, Carolei A, Wysocki WM, Costa A. Necrotic complications after nipple- and areolasparing mastectomy. World J Surg 2006;30:1410-3.

4. Endara M, Chen D, Verma K, Nahabedian MY, Spear SL. Breast reconstruction following nipple-sparing mastectomy: a systematic review of the literature with pooled analysis. Plast Reconstr Surg 2013;132:1043-54.

5. Kim HR, Lim JS, Kim SM, Jung SN, Yoo G, Rha EY. One-stage nipple and breast reconstruction following areola-sparing mastectomy. Arch Plast Surg 2013;40:553-8.

6. Tan BK, Chim H, Ng ZY, Ong KW. Aesthetic design of skinsparing mastectomy incisions for immediate autologous tissue breast reconstruction in asian women. Arch Plast Surg 2014;41:366-73.

7. American Society of Plastic Surgeons. Reconstructive plastic surgery statistics Internet. American Society of Plastic Surgeons cited 2015 May 3. Available from: http://www.plasticsurgery.org/Documents/medical-professionals/healthy-policy/ evidence-practice/breast-reconstruction-expanders-withimplants-guidelines.pdf.

8. Moyer HR, Ghazi B, Daniel JR, Gasgarth R, Carlson GW. Nipple-sparing mastectomy: technical aspects and aesthetic outcomes. Ann Plast Surg 2012;68:446-50.

9. van Deventer PV. The blood supply to the nipple-areola complex of the human mammary gland. Aesthetic Plast Surg 2004;28:393-8.

10. Gerber B, Krause A, Dieterich M, Kundt G, Reimer T. The oncological safety of skin sparing mastectomy with conservation of the nipple-areola complex and autologous reconstruction: an extended follow-up study. Ann Surg 2009;249:461-8.

11. Kneubil MC, Lohsiriwat V, Curigliano G, Brollo J, Botteri E, Rotmensz N, et al. Risk of locoregional recurrence in patients with false-negative frozen section or close margins of retroareolar specimen in nipple-sparing mastectomy. Ann Surg Oncol 2012;19:4117-23.

12. Gould DJ, Hunt KK, Liu J, Kuerer HM, Crosby MA, Babiera G, et al. Impact of surgical techniques, biomaterials, and patient variables on rate of nipple necrosis after nipple-sparing mastectomy. Plast Reconstr Surg 2013;132:330e-8e.

13. Dent BL, Small K, Swistel A, Talmor M. Nipple-areolar complex ischemia after nipple-sparing mastectomy with immediate implant-based reconstruction: risk factors and the success of conservative treatment. Aesthet Surg J 2014;34:560-70. 